Friedmann, Rosa \& Epstein, C. (1951). J. gen. Microbiol. 5, 830-839.

\title{
The Assay of the Antibiotic Nisin by Means of a Reductase (Resazurin) test
}

\author{
By ROSA FRIEDMANN AND C. EPSTEIN \\ Fison's Research Laboratories, Loughborough, and Holmes Chapel
}

SUMMARY : The familiar resazurin test used in milk testing has been adapted to the estimation of nisin, using a fast-growing strain of Streptococcus cremoris as test organism. The reproducibility and accuracy of this test compares favourably with the many other assay methods for nisin which use Strep. agalactiae as test organism. Results may be obtained in less than an hour as compared with $15-48 \mathrm{hr}$. in the other tests and are a measure of bactericidal power only. Aseptic technique during the actual assay procedure is unnecessary. Methods were devised to ensure a suitable standard inoculum, which is imperative for this test. As little as 0.5 unit nisin $/ \mathrm{ml}$. may be estimated.

Inhibition of reductase activity and acid production by bacteria in milk have been used for the assay of penicillin and streptomycin. Reid \& Brewer (1946) used Bacillus subtilis as test organism and added methylene blue as indicator system at the beginning of incubation. Approximate readings were possible after $4 \mathrm{hr}$. and final readings were taken after $18 \mathrm{hr}$. Sanchez \& Lamensans (1947) used Lactobacillus bulgaricus as test organism. Their indicator system was a solution containing methyl red and methylene blue, drops of which were added every $30 \mathrm{~min}$. to control tubes. The test could usually be completed within $2 \frac{1}{2} \mathrm{hr}$. Hirsch (1950) quotes a similar test as a rough guide for nisin activity, again using methylene blue as indicator, the test organism being a fast-growing strain of Strep. cremoris (1P5). The use of such a very fastgrowing and sensitive organism (about four times as sensitive as Strep. agalactiae; Hirsch, 1950) makes it difficult to obtain a stable end-point; this is easily overshot if a reasonably accurate and therefore narrow dilution range is chosen. A graded response as obtainable with resazurin as indicator is therefore preferable to the all-or-nothing response of methylene blue. Moreover, methods must be devised to ensure a reasonably constant inoculum with regard to growth phase and number of bacteria. We have attempted to embody these requirements into a method which could be used on a routine scale with a minimum of labour, apparatus and experience.

\section{MATERIALS}

Cultures. Fast-growing strains of Strep. cremoris were used. The original N.I.R.D. strain ' 1 P5' became somewhat sluggish and was eventually replaced by ' $\mathrm{T} 17$ ', a cheese-starter organism recently isolated from a culture from a Cheshire cheese factory. Doubtless many other strains would prove suitable. Subculture $(0 \cdot 1 \%, v / v)$ was carried out every $24 \mathrm{hr}$. in the sterile milk medium given below. Incubation was at $30^{\circ}$.

Medium. Spray-dried skim milk (120 g.; Benger's Ltd., Coleraine) was reconstituted as a $12 \%(\mathrm{w} / \mathrm{v})$ solution in tap water. Volumes of $800 \mathrm{ml}$. were 
adjusted to $\mathrm{pH} 6.8$ and sterilized by steaming for $30 \mathrm{~min}$. on three successive days.

Resazurin solution. Five tablets weighing 0.12 g. each (Benger's Ltd.) were dissolved in $100 \mathrm{ml}$. glass-distilled water. Solutions were made up daily; they must be shielded from light.

Standards. A sample of partially purified nisin served as the master standard for all the work to be described. In collaboration with Dr Hirsch, according to the original definition of the nisin unit (Mattick \& Hirsch, 1947) and using the original method of assay (dilution method; Mattick \& Hirsch, 1947), 10,000 units/mg. have been attributed to this powder. Standards and subsidiary standard powders were stored at $12^{\circ}$. Fresh standard solutions containing, 10,000 units $/ \mathrm{ml}$. were prepared weekly in $0.05 \mathrm{~N}-\mathrm{HCl}$ and stored at $12^{\circ}$.

Samples for assay and diluent. Powders were dissolved in $0.05 \mathrm{~N}-\mathrm{HCl}$ and dilutions made in the sterile milk medium given above.

\section{METHODS}

Principle. The rate of reduction of resazurin in milk is indicative of the number of organisms present and was first used by Pesch \& Simmert (1929) as a rapid and simple method for grading milk. Davis (1939) developed the test which was eventually made the basis of the official standard method in Great Britain (Ministry of Agriculture \& Fisheries, 1943). Non-bacterial reducing systems interfere because of the extreme sensitivity of the dye which, on the other hand, ensures the great rapidity of the method.

Standard inoculation of sterile milk with a nisin-sensitive organism ensures a standard base-line activity modifiable by the action of the antibiotic. Reductase activity of other systems in the milk would raise this base-line, but not interfere with the test. The amount of antibiotic present is clearly indicated by the well-known colour changes of the dye; tubes containing sufficient nisin for the complete inhibition of the test organism show the unchanged blue colour of the control tubes containing the uninoculated sterile milk. Various possible methods were considered, and eventually the following was worked out.

\section{PROCEDURE}

Samples of nisin (5-15 mg.) are weighed out (torsion balance) and solutions made up to contain $1 \mathrm{mg}$. $/ \mathrm{ml}$. Preliminary dilutions of these solutions are made in sterile milk such that $1 \mathrm{ml}$. of final dilution contains between 5 and 50 units of nisin. Graded volumes (0.1-1.0 ml. with normally $33 \%$ differences; $10 \%$ for very accurate work) of this dilution are accurately measured into successive tubes, followed by (on a routine scale) $4.6 \mathrm{ml}$. of the cold $\left(2-4^{\circ}\right)$ inoculated milk. A burette with a wide orifice is used for adding this bulk-inoculated milk, standardized as discussed below. Mixing is achieved by quick tipping of each tube, and the racks are then incubated for $15 \mathrm{~min}$. at $30^{\circ}$. Not more than two racks (fifty tubes) are prepared by any one worker at one time because of the quick growth of the test organism. At least one standard series covering the range from 0.5 to 5 units/ml. is included with each set of tubes (two racks, 
fifty tubes). After $15 \mathrm{~min}$. the racks are taken out of the bath (incubator) and $1.0 \mathrm{ml}$. of resazurin solution added to each tube. This addition must be carried out as quickly as possible, but need not be very accurate. Blow-out pipettes with very large orifices were used. Immediately after each addition the tube must be inverted by an assistant. The racks are then quickly returned to the bath for at least $5 \mathrm{~min}$. to allow for colour development. Incubation is continued until a mauve to mauve-pink coloration is reached in the $1 \mathrm{unit} / \mathrm{ml}$. standard tube. At this stage, the tubes are taken out and the colours noted. The following colour range (with the symbols used for scoring) is used: blue, $\mathbf{B}$; mauve, M; mauve-pink, MP; pink-mauve, PM; strong pink, SP ; light pink, LP; white, $\mathbf{W}$. The $\mathbf{B} \rightarrow \mathbf{M}$ change gives the most reliable end-point. Blue corresponds for all practical purposes to 'all organisms killed' and is stable in the dark. Evaluation is therefore based on the first mauve tube (next to the last blue tube) as the end-point. The other tubes are, however, also taken into account, and matching may be carried out with the MP or PM tube as the endpoint, although this is more difficult. Under the conditions of the test MP and PM tubes may change to $\mathbf{P}$ within $5 \mathrm{~min}$. The $\mathbf{P} \rightarrow W$ change is more gradual but reversible, and is therefore contra-indicated as an end-point. It may however, serve as a first useful approximation to the true value of the sample. ' $W$ ' should not occur in the standard range. The tubes were usually covered with glass caps or metal caps, but may be used uncovered. As the test is completed in 15-20 min. there is no need for aseptic precautions. Table 1 gives a protocol of an actual test.

\section{Choice of inoculated milk for the test}

Preliminary trials with the methylene-blue test (Hirsch, 1949) and the resazurin test gave extremely variable results. Not only is it difficult to ensure an optimum population every day, but the correct phase of growth for the action of nisin was at first unknown. Later experiments (see under 'Mode of action') confirmed first impressions that nisin acts on the actively growing organisms only. The following working scheme was devised to ensure reproducibility of population in the correct phase of growth for the purposes of our test, such that the end-point falls within the chosen test range and good colour differentiation is achieved between two neighbouring tubes. Each morning a 2.5 , a 5 and a $10 \%$ inoculum was made in sterile milk from a $24 \mathrm{hr}$. culture in milk and incubated for $1 \frac{1}{2} \mathrm{hr}$. at $30^{\circ}$, by which time it was in the log-phase. Further growth was then stopped by cooling in ice water and storing in the ice chest. The milk for the day's use was then chosen in the following manner:

(1) $5 \mathrm{ml}$. of each batch of milk were added to three test-tubes, $1 a$ (10\% inoculum), $1 b$ (5\% inoculum) and $1 c(2.5 \%$ inoculum), followed by $1 \mathrm{ml}$. of resazurin solution. The contents were quickly mixed by tipping and the colours allowed to develop for $5 \mathrm{~min}$. at $30^{\circ}$. After this incubation the colours were quickly read and noted. (2) $0.2 \mathrm{ml}$. quantities of a $1 / 20$ dilution in sterile milk of a standard solution containing 500 units nisin/ml. were added to tubes $2 a, 2 b$ and $2 c$. (3) $0 \cdot 15 \mathrm{ml}$. quantities of the same $1 / 20$ dilution were added to tubes $3 a, 3 b$ and $3 c$. (4) $5 \mathrm{ml}$. of the $10 \%$ batch of milk were then added to 


\section{Table 1. Protocol of a test}

(Symbols refer to the scoring of colour changes; see p. 832.)

Choice of size of inoculum for the given sample of milk

A solution of standard nisin (10,000 units/mg.) was made up to contain $1 \mathrm{mg} . / \mathrm{ml}$. Dilutions of this solution were made in the sterile milk medium and added in different volumes to the variously inoculated milk media.

$\overbrace{\begin{array}{cc}10 \\ (a)\end{array}}^{\text {Volume of inoculum }(\%, \mathrm{v} / \mathrm{v})}$

\section{Composition of test}

(1) Control; no nisin. $5 \mathrm{ml}$. of milk + $1 \mathrm{ml}$. resazurin; reading after $5 \mathrm{~min}$. incubation

(2) $5 \mathrm{ml}$. of milk $+0 \cdot 2 \mathrm{ml}$. of $1 / 400$ dilution of nisin solution $+1 \mathrm{ml}$. resazurin; readings after $15 \mathrm{~min}$. incubation

(3) $5 \mathrm{ml}$. of milk $+0 \cdot 15 \mathrm{ml}$. of $1 / 400$ dilution of nisin solution $+1 \mathrm{ml}$. resazurin; readings after $15 \mathrm{~min}$. incubation.

\begin{tabular}{|c|c|c|}
\hline $\mathbf{P}$ & $\mathbf{M}$ & B \\
\hline PM & $\mathbf{M}$ & B \\
\hline $\mathbf{P M}$ & MP & $\mathbf{M}$ \\
\hline
\end{tabular}

The inoculated milk of choice was therefore that containing $2.5 \%(v / v)$ of inoculum, because the resazurin was not reduced in the control tube (no nisin) after 5 min. incubation, and this dilution of inoculum showed the most marked colour difference between the $0 \cdot 15$ and $0 \cdot 20 \mathrm{ml}$. doses of the $1 / 400$ dilution of nisin solution, namely $B \rightarrow M$.

Test with chosen inoculum size $(2.5 \%, v / v)$ in the given milk

Dilutions of the samples refer to solutions containing $1 \mathrm{mg} . / \mathrm{ml}$.

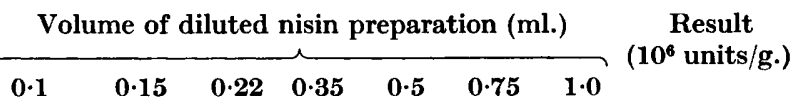

Samples (dilutions)

Standard (1/400)

Sample 102.1 (1/40)

Gel $323(1 / 4)$

Sample $100.1212(1 / 800)$

Sample 87.1212 (1/800)

Sample $90.2(1 / 400)$

Sample $91.2(1 / 400)$

Standard (1/400)
Colour of resazurin in test

$\begin{array}{lllllllc}\text { PM } & \text { MP } & \text { M } & \text { B } & \text { B } & \text { B } & \text { B } & \text { 10 (Assumed) } \\ \text { PM } & \text { MP } & \text { M } & \text { B } & \text { B } & \text { B } & \text { B } & \mathbf{1} \\ \text { MP } & \text { M } & \text { B } & \text { B } & \text { B } & \text { B } & \text { B } & \mathbf{0} \cdot 147 \\ \text { SP } & \text { PM } & \text { MP } & \text { M } & \text { B } & \text { B } & \text { B } & \mathbf{1 2 \cdot 6} \\ \text { MP } & \text { M } & \text { B } & \text { B } & \text { B } & \text { B } & \text { B } & \mathbf{2 9 \cdot 4} \\ \text { LP } & \text { P } & \text { SP } & \text { PM } & \text { MP } & \text { M } & \text { B } & \mathbf{2 \cdot 9 5} \\ \text { W } & \text { W } & \text { W } & \text { LP } & \text { LP } & \text { LP } & \text { P } & <2 \cdot 2(\text { ?) } \\ \text { PM } & \text { MP } & \text { M } & \text { B } & \text { B } & \text { B } & \text { B } & 10\end{array}$

tubes $2 a$ and $3 a, 5 \mathrm{ml}$. of the $5 \%$ batch to tubes $2 b$ and $3 b$ and $5 \mathrm{ml}$. of the $\mathbf{2 . 5} \%$ batch to tubes $2 c$ and $3 c$. (5) After mixing the contents, all six tubes were incubated for $15 \mathrm{~min}$. at $30^{\circ}$. (6) The tubes were then removed from the water-bath, $1 \mathrm{ml}$. of the resazurin solution added to each tube, the contents mixed once more and returned to the bath for another $5 \mathrm{~min}$. The colours were then noted.

The milk of choice should be such that one of the tubes in (1) contains enough organisms to impart a pinkish tint while the next tube, containing milk inoculated with half the number of organisms, should not show any pink tints. 
None of the tubes in (2) or (3) must go white. If that does happen, a $1 / 2$ dilution in sterile milk may be resorted to and a fresh start made, although such a procedure has not always been satisfactory. The pair of tubes $(2 a-3 a$ or $2 b-3 b$ or $2 c-3 c$ ) showing the biggest difference in colour indicates the optimum growth phase and contains usually the batch of milk giving MP tint in (1). This milk is chosen for the day's use and maintained at 8-10 ${ }^{\circ}$. It may, if necessary, be used also on the following day if kept in the refrigerator, but will certainly give slightly more reduction, i.e. shorter incubations will be necessary; it is always kept in the refrigerator except when actually adding it to the test solutions. Table 1 contains a protocol of an actual test.

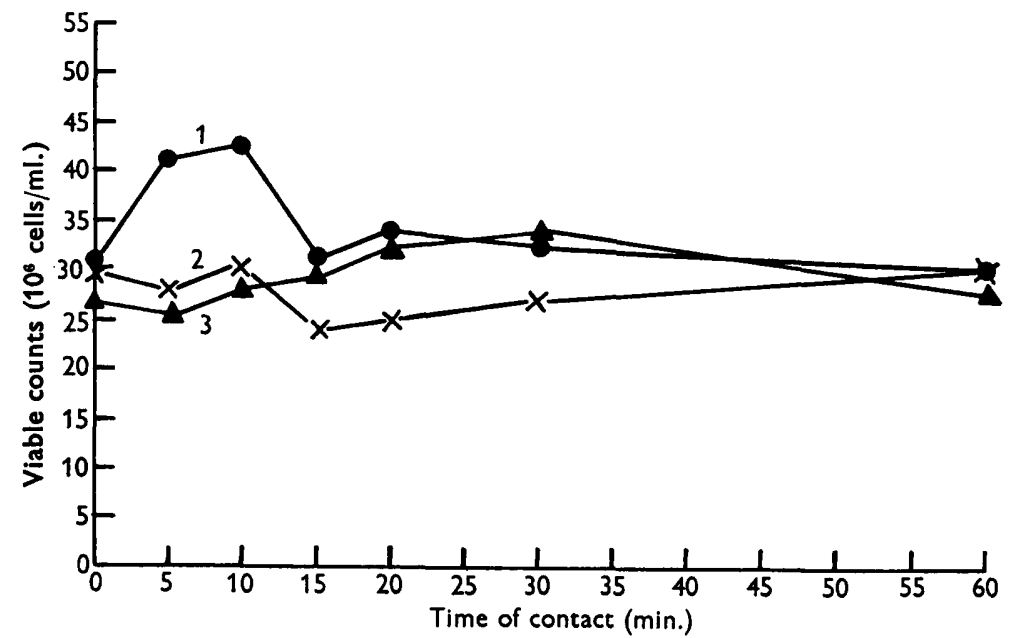

Fig. 1. The effect of 1 and 2 units nisin $/ \mathrm{ml}$. on Strep. cremoris in the lag-phase. Curve 1 (-), no nisin addition; curve $2(x-x), 1$ unit nisin/ml.; curve $3(\Lambda-\Lambda), 2$ units nisin $/ \mathrm{ml}$.

\section{Mode of action of nisin}

Viable counts were taken after leaving 1-2 units nisin $/ \mathrm{ml}$. in contact with: (a) freshly inoculated milk at $15^{\circ}$ (Fig. 1); (b) freshly inoculated milk at $30^{\circ}$; (c) the same milk after $1 \frac{1}{2} \mathrm{hr}$. incubation at $30^{\circ}$. The organisms in $(a)$ were thus in the lag-phase throughout the time of contact, while those in $(b)$ were allowed to proceed into the log-phase during contact. Organisms in $(c)$ started contact with nisin in the log-phase. Fig. 1 shows that, as expected, no significant decrease occurred in the viable counts during the lag-phase. These results were confirmed (Table 2) in a repeat of the experiment with a lower initial cell count in the presence of 2 units nisin/ml. In experiment $(b)$, the total viable count in fact increased within $30 \mathrm{~min}$. incubation at $30^{\circ}$ from $4.7 \times 10^{6}$ viable cells $/ \mathrm{ml}$. to $900 \times 10^{6}$ viable cells $/ \mathrm{ml}$. despite the presence of 10 units nisin $/ \mathrm{ml}$. After $2 \mathrm{hr}$. incubation, i.e. after about $30 \mathrm{~min}$. contact of cells in the log-phase with nisin (intermediate counts not taken), the count dropped to $<10,000$ cells $/ \mathrm{ml}$. In experiment $(c)$, a rapid decrease in count occurred within 10 min. (Table 3). Mattick \& Hirsch (1947) noted that Strep. agalactiae was killed within $10 \mathrm{~min}$. The present tests therefore suggest that nisin exerts its 
Table 2. The effect of 2 units nisin/ml. on Streptococcus cremoris in the lag-phase

$\begin{array}{cc}\begin{array}{c}\text { Time of contact } \\ \text { (min.) }\end{array} & \begin{array}{c}\text { Viable count } \\ \left(10^{6} \text { cells } / \mathrm{ml} \text { ) }\right.\end{array} \\ 0 & 4 \cdot 2 \\ 2 & 8 \cdot 3 \\ 5 & 2 \cdot 4 \\ 10 & 3 \cdot 1 \\ 25 & 7 \cdot 5 \\ 60 & 2 \cdot 4\end{array}$

Table 3. The effect of nisin on Streptococcus cremoris in the log-phase

\begin{tabular}{|c|c|c|}
\hline \multirow{2}{*}{$\begin{array}{c}\text { Time } \\
\text { of contact } \\
\text { (min.) }\end{array}$} & \multicolumn{2}{|c|}{ Nisin concentration } \\
\hline & $\begin{array}{l}2 \text { units } / \mathrm{ml} . \\
\text { Viable coun }\end{array}$ & $\begin{array}{l}10 \text { units } / \mathrm{ml} \text {. } \\
\left.10^{6} \text { cells } / \mathrm{ml} .\right)\end{array}$ \\
\hline 0 & $8 \cdot 3$ & $9 \cdot 5$ \\
\hline 2 & 5.7 & - \\
\hline $\mathbf{5}$ & $\mathbf{3 \cdot 2}$ & - \\
\hline 10 & 0.8 & $0 \cdot 2$ \\
\hline 20 & 一 & 0.01 \\
\hline 25 & 0.7 & - \\
\hline 30 & - & 0.08 \\
\hline
\end{tabular}

bactericidal action on the actively-growing organisms only. Hirsch's finding (1950) that nisin delays the lag-phase, implying that there is some action on the resting bacteria, may have been a reflexion of the speed with which nisin kills organisms entering the log-phase. This would cause an apparent lag-phase.

\section{Accuracy of the test}

Powder $138 \mathrm{~A}$ was assayed 21 times giving a mean value of 25,800 units/mg. and a standard deviation for a single determination of 5740. The standard error was $2500(P=0.95)$ or $10 \%$. Calculations of the standard error for a period of over a year of routine testing showed variations from between \pm 7 and $\pm \mathbf{2 0} \%$ for six repeat assays, and with percentage differences of about $\mathbf{3 3} \%$ between any two consecutive tubes (as illustrated in Table 1). Repeats carried out by one experienced tester only, usually yield absolutely reproducible results on the given (wide) scale. In order to obtain a measure of the possible accuracy of the test, percentage differences were adjusted to $10 \%$ for a given powder which was assayed every day for 2 weeks. A factor of $10 \%$ represents the limits for colour assessment. A standard deviation of $10.7 \%$ and a standard error of $6.8 \%(P=0.95)$ was obtained for the ten repeats (cf. Table 5 , blend $M$ ).

\section{Adaptation for use as a serial dilution test in micro-tubes}

The possibility for a rough test in micro-tubes $(75 \times 8 \mathrm{~mm}$.) was investigated, using a modified procedure. The resazurin was incorporated in the inoculated milk used in the serial dilutions. The desirable mauve end-point cannot be obtained under these conditions and we had to rely on the less stable 
pink $\rightarrow$ white end-point. However, in practice it was found that this end-point is very much more stable in micro-tubes (since there is a very small surface exposed to air) than in the $15 \times 1.8 \mathrm{~cm}$. test-tubes usually used; in fact, colours remained unaltered for up to $6 \mathrm{hr}$. at $30^{\circ}$. On incubation overnight the contents of some of the tubes solidified, giving an additional end-point.

The following procedure was worked out. (1) Dilutions are made in sterile milk. The samples are diluted to contain about $100 \mathrm{units} / \mathrm{ml}$. (2) To $100 \mathrm{ml}$. inoculated milk (at $2-4^{\circ}$ ) $20 \mathrm{ml}$. of resazurin solution (prepared as in the macro test) are added. The mixture should exhibit a mauve tint. When the colour turns pink immediately, too many organisms are present and further dilution with sterile milk may be made. (3) $0.5 \mathrm{Ml}$. of the inoculated milk + resazurin is added to each tube. (4) $0.5 \mathrm{Ml}$. of the diluted sample is added to the 1st tube of each series and serial dilutions carried out. (5) Incubation at $30^{\circ}$ is allowed to proceed for about $1 \mathrm{hr}$. until no further colour change is noticeable. (6) The colours are recorded. A standard is included with each set of twelve tests and the results are obtained by comparison with the standard as in the macro test.

The accuracy of this test is low, but reproducibility is good and it is a very convenient test for quick assessment. Samples of low unitage cannot, however, be assayed by this method, and no attention should be paid to the first three tubes, since acids and other interfering substances may not be sufficiently diluted out.

\section{The effect of impurities on the assay}

Hirsch (1950) stated that culture fluids containing nisin are very much more difficult to assay by the lag-phase method than are pure nisin preparations. It is obvious that such interference must be expected in a diffusion type of assay and was indeed found. When assaying penicillin solutions, it is possible to destroy the antibiotic by a penicillinase and then to test the effect of the medium alone on the test. This is not possible with nisin since so far a 'nisinase' has not been found. We therefore carried out the following experiment. Our standard solution of nisin $(10,000$ units $/ \mathrm{ml}$.) was diluted 20 -fold with (a) $0.05 \mathrm{~N}-\mathrm{HCl}$; $(b)$ culture medium before inoculation as used in the large-scale production of nisin; $(c)$ culture fluid after nisin fermentation, assaying 600 units/ml.; $(d)$ fermented culture fluid taken on an occasion when the fermentation had accidentally gone wrong and vigorous growth of producer organism had taken place without nisin formation. The assay result showed 500 units $/ \mathrm{ml}$. in cases $(a),(b)$ and $(d)$ and 1000 units $/ \mathrm{ml}$. in case $(c)$, indicating that neither fermented nor sterile broth interfered with the test, nor the substances produced during the abnormal fermentation. It has been confirmed many times that the dilution, diffusion and lag-phase methods tend to give irregular results with crude culture fluids, while the resazurin method (macro test) usually gave results which were confirmed afterwards by the nisin yields obtained from the cultures.

Influence of acetone- $\mathrm{HCl}$. During preliminary isolation experiments of nisin from fermented liquors, charcoal columns were eluted with $65 \%(v / v)$ acetone in water containing also $2 \%(v / v)$ of concentrated hydrochloric acid, the eluates collected and assayed before and after removal of acetone- $\mathrm{HCl}$ in 
vacuo $\left(30^{\circ}\right)$. The results are given in Table 4. With one exception (sample $18 \mathrm{E} 2$ ) the agreement was satisfactory. The nisin concentration of the eluates before removal of acetone was of the order of 200 units $/ \mathrm{ml}$. The conclusion that the $65 \%$ acetone-HCl mixture did not interfere even at this low concentration of nisin seems justified.

Table 4. The assay of nisin in the presence and absence of acetone- $\mathrm{HCl}$ (single assays)

$\begin{array}{lcc}\text { Sample } & \begin{array}{c}\text { Before removal of } \\ \text { acetone-HCl } \\ \text { (units) }\end{array} & \begin{array}{c}\text { After removal of } \\ \text { acetone-HCl } \\ \text { (units) }\end{array} \\ \text { 14E } & 12,300 & 8,200 \\ \text { 14 H } & 9,400 & 9,250 \\ \text { 18 E 1 } & 37,200 & 34,100 \\ \text { 18 E2 } & 38,400 & 94,000 \\ \text { 18 E3 } & 10,000 & 10,600\end{array}$

\section{DISCUSSION}

The diversity of methods proposed for the estimation of nisin is a reflexion of the existing state of dissatisfaction. The plate-count method (Hirsch, 1950) is too cumbersome for routine testing and has very large limits of error. The 'dilution' method (Mattick \& Hirsch, 1947) has been used as a routine by us for several years. Unfortunately, under the conditions of the test, nisin is very readily and strongly adsorbed on to the glass walls (or to impurities sticking to the glass walls). As much as 2 units/ml. have been yielded up to sterile fresh broth placed in such vessels. Even boiling with detergents and alkaline or acidoxidizing agents has not always been successful in removing the antibiotic, and the continuous use of new tubes is impracticable on a routine scale. The lagphase method (Hirsch, 1950) has proved even worse on a routine scale. Its name is a misnomer: special precautions are taken to ensure that the test organism is in its most actively growing phase at the beginning of the test. It is also stated that finally 'the response due to the formation of resistant strains' was 'preferred to the lag-phase response'. In our opinion, however, this production of resistant strains constitutes only a modifying feature superimposed upon the usual direct bactericidal action of nisin on organisms in the log-phase (see Fig. 1). The test necessitates $\mathrm{pH}$ measurements within $0 \cdot 1$ of a pH unit, and the length of incubation has to be timed very accurately to obtain maximum differences of acidity between any two nisin concentrations. The response due to formation of resistant strains and that due to killing of the sensitive cells run in opposite directions, and the process of acid production is self-limiting; eventually all the cultures reach the same $\mathrm{pH}$. In the diffusion method (Friedmann \& Beach, 1950) diffuse zones were at times obtained with impure powders (similar interferences quoted for the lag-phase method) and the routine range is rather higher (100-1000 units) than in the other methods, although solutions down to $10 \mathrm{units} / \mathrm{ml}$. could be assayed on a different range. 
That method has nevertheless proved very convenient for routine purposes, although the limits of error are large unless many repeats are carried out; assay results cannot be obtained in less than $48 \mathrm{hr}$.

In all the methods just mentioned Strep. agalactiae is used as test organism. The use of the very fast-growing Strep. cremoris made the rapid methylene blue and resazurin tests possible. The short duration is justified owing to the very rapid bactericidal action of nisin on organisms in the log-phase. Thanks to the great sensitivity of the test organism and the low nisin concentration at which the test can therefore be carried out, impurities are readily diluted out in the highly buffered milk medium during the preliminary dilutions, resulting in less interference than in the other tests. 'Tube trouble', due to the adsorption of nisin on glass, has not been encountered, whether due to the different medium, the much shorter time of contact or for other reasons.

\section{Table 5. A comparison of assay results obtained with the diffusion, resazurin, dilution and lag-phase methods}

(Results for solids are expressed as $\times 10^{-3}$ units/g., those for 'brews' (specially indicated) in units/ml., and are given as arithmetic means \pm standard error (in $\%$ ) for $\boldsymbol{P}=\mathbf{0 . 9 5}$. The number of single determinations is given in brackets. For the diffusion and lag-phase methods, these numbers are given as $10 \times 5$ and $10 \times 3$ respectively rather than as 50 and 30 , since any one assay result in these tests is derived from 5 and 3 single estimations respectively.)

Method of assay used

$\overbrace{\text { Diffusion }}^{\begin{array}{c}\text { Resazurin } \\ \text { Laboratory where tested }\end{array}}$ Dilution Lag-phase

\begin{tabular}{|c|c|c|c|c|c|c|}
\hline Sample & $\begin{array}{c}\text { Holmes } \\
\text { Chapel }\end{array}$ & $\begin{array}{l}\text { Lough- } \\
\text { borough }\end{array}$ & $\begin{array}{l}\text { Holmes } \\
\text { Chapel }\end{array}$ & $\begin{array}{l}\text { Lough- } \\
\text { borough }\end{array}$ & $\begin{array}{c}\text { Holmes } \\
\text { Chapel }\end{array}$ & $\begin{array}{l}\text { Lough- } \\
\text { borough }\end{array}$ \\
\hline Blend $\mathbf{M}$ & $\begin{array}{c}7100 \pm 10 \\
(10 \times 5)\end{array}$ & $\begin{array}{c}5800 \pm 12 \cdot 6 \\
(14 \times 5)\end{array}$ & $\begin{array}{c}6400 \pm 25 \cdot 6 \\
(6)\end{array}$ & $\begin{array}{c}6500 \pm 10 \cdot 2 \\
(12) \\
6400^{*} \pm 6 \cdot 8 \\
(10)\end{array}$ & $\begin{array}{c}650 \pm 28 \\
(4)\end{array}$ & - \\
\hline $138 \mathrm{~A}$ & $\begin{array}{c}21400 \pm 25 \cdot 2 \\
(13 \times 5)\end{array}$ & $\begin{array}{c}21500 \pm 7 \\
(14 \times 5)\end{array}$ & $\begin{array}{c}27000 \pm 12 \cdot 2 \\
(10)\end{array}$ & $\begin{array}{l}24000 \pm 6 \cdot 4 \\
(10)\end{array}$ & $\begin{array}{c}12400 \pm 18 \cdot 4 \\
(5)\end{array}$ & $\begin{array}{c}14500 \pm 11 \\
(18 \times 3)\end{array}$ \\
\hline 105 & - & $\begin{array}{c}905 \pm 10 \cdot 4 \\
(16 \times 5)\end{array}$ & - & $\begin{array}{l}677 \pm 10 \cdot 6 \\
(12)\end{array}$ & - & - \\
\hline 783 & - & - & $\begin{array}{c}28500 \pm 16 \\
(6)\end{array}$ & - & $\begin{array}{c}27500 \\
(6)\end{array}$ & - \\
\hline 118 & - & - & $\begin{array}{c}9700 \pm 4 \\
(10)\end{array}$ & $\begin{array}{c}9900 \pm 06 \\
(10)\end{array}$ & $\begin{array}{c}9200 \pm 7 \\
(9)\end{array}$ & - \\
\hline 5.21 I & - & $\begin{array}{c}6100 \pm 14 \\
(7 \times 5)\end{array}$ & - & $\begin{array}{c}6100 \pm 9 \\
(6)\end{array}$ & - & $\begin{array}{c}7000 \pm 40 \\
(6 \times 3)\end{array}$ \\
\hline Wr1A & - & $\begin{array}{c}2540 \pm 13 \cdot 6 \\
(10 \times 5)\end{array}$ & - & - & 一 & $\begin{array}{c}2850 \pm 30 \\
(9 \times 3)\end{array}$ \\
\hline Brew X & - & $\begin{array}{r}247 \pm 14 \\
(12 \times 5)\end{array}$ & - & $\begin{array}{c}231 \pm 6 \cdot 6 \\
(12)\end{array}$ & - & - \\
\hline Brew 112 & 一 & - & $\begin{array}{c}233 \pm 12 \\
(5)\end{array}$ & - & $\begin{array}{c}194 \times 46 \\
(6)\end{array}$ & - \\
\hline
\end{tabular}

Note. The only statistically significant discrepancy (' $t$ '-test) occurs with powder $138 \mathrm{~A}$, where the dilution and lag-phase methods gave lower results than the diffusion and resazurin methods, and has remained unexplained: neither unhydrolysed nor hydrolysed $138 \mathrm{~A}$ could be distinguished chromatographically from other powders of similar purity. The same test organism was used in the dilution, lag-phase and diffusion methods. 
The test has proved suitable for measuring nisin in body fluids (Bavin, Falconer, Friedmann \& Robson, 1951). The short duration of the test militates against interference due to the formation of resistant strains (necessarily forming a mixed population in all the other tests) or to the growth of contaminating bacteria. This speed has also been an advantage in stability testing since inactivations due to assay conditions are decreased to a minimum. It must, however, be emphasized that the strict standardization described is of paramount importance.

In Table 5 statistically analysed results for the four assay methods have been computed for nisin of varying degrees of impurity, and also crude culture fluids containing nisin. As far as the bulk of our assays over a period of about 2 years go, we feel justified in saying that no significant differences exist between the results obtained by the different methods, which thus all appear to measure the same entity. Apparent differences could usually be traced to different degrees of accuracy.

We have much pleasure in thanking: Dr Falconer for encouraging interest and useful criticisms; Dr Hirsch for interesting discussions; Mr A. S. Beach and staff of the Loughborough laboratories for carrying out some experiments relating to the mechanism of action of nisin and for allowing us to use data gained with the lagphase and diffusion methods for our statistical analysis; Miss P. D. R. Smith and Miss P. Jewell for technical assistance; Messrs Fisons Ltd. for permission to publish.

\section{REFERENCES}

Bavin, E. M., Falconer, R., Friedmann, R. \& Robson, J. M. (1951). Nisin in experimental tuberculosis. (In preparation.)

Davis, J. G. (1939). Grading milk by Resazurin test. Food Manuf. 14, 196.

Friedmann, R. \& Beach, S. A. (1950). New methods of assay for the antibiotic nisin. J. gen. Microbiol. 5, v.

Hrrsch, A. (1950). The assay of nisin. J. gen. Microbiol. 4, 70.

Mattick, A. T. R. \& Hirsch, A. (1947). Further observations on an inhibitory substance (nisin) from lactic streptococci. Lancet, ii, 5.

Ministry of Agriculture \& Fisheries (1943). National milk testing and advisory scheme: The routine Resazurin test. Technique nos. C158/T.P.Y. and C150/T.P.Y.

Pesch, K. L. \& Srmmert (1929). Untersuchungen über den Frischheitszustand der Milch. Bestimmung der Wasserstoffionenkonzentration und der Reduktionszeit. Milchw. Forsch. 8, 551.

REID, R. D. \& BREwER, J. H. (1946). The reductase method for the determination of penicillin concentration in body fluids. J. Bact. 52, 251.

Sanchez, G. \& Lamensans, A. (1947). Méthode de dosage rapide de la pénicilline et de la streptomycine. C.R. Acad. Sci., Paris, 224, 1189. 